\title{
Integrity of Uterine Arteries: A Key for Pregnancy after Fibroid Embolization
}

\author{
Alexandre Laurent ${ }^{1 *}$, Laurence Moine ${ }^{2}$, Laurent Bédouet ${ }^{3}$, Michel Wassef ${ }^{4}$ \\ ${ }^{1}$ Département de Neuroradiologie, HP Hôpital Lariboisière, France \\ ${ }^{2}$ Institut Galien Paris-Sud, CNRS, Université Paris-Saclay, France \\ ${ }^{3}$ Occlugel SAS, France \\ ${ }^{4}$ Département d'Anatomopathologie, AP-HP Hôpital Lariboisière, France
}

Submission: April 14, 2017; Published: June 01, 2017

*Corresponding author: Alexandre Laurent, Département de Neuroradiologie, Hôpital Lariboisière, 2 rue Ambroise Paré, 75010 Paris, France, Email: dr.alex.laurent@gmail.com

\section{Summary}

Particles used today to occlude uterine arteries in fibroids management cannot guarantee a full anatomical and functional recovery of these arteries as they should for women willing to conceive. New resorbable materials could constitute a serious alternative.

\section{Text}

Uterine fibroid embolization (UFE) consists of blocking the blood flow of uterine arteries (UA) with small particles to generate an ischemic necrosis of the fibroids (leiomyomas) present in uterus. UFE has been offered initially to a majority of women over the age of 40 at the time of treatment, i.e. to a population of women generally not interested in future pregnancy. UFE is now commonly proposed as an organ preserving treatment to a population of younger women willing to conceive.

In this context, a serious concern is the fate of the UA after embolization. Their anatomical integrity and functional preservation is of crucial importance for future pregnancy, since their number and diameter shall drastically increase to supply nutrients and oxygen for foetal and placental growth and any reduction of flow during pregnancy may be pejorative. Intrauterine growth retardation is clearly linked to a reduction of UA flow, for example after hypogastric artery ligation [1,2] or after UFE $[3,4]$.

The particles used for embolization are mostly non degradable materials which generate a chronic inflammation and vessel damage. The UA recanalization rate is limited to $50 \%$ to $77 \% 6$ months after embolization with poly (vinyl-alcohol) particles $[5,6]$. These particles act as durable obstacle in the UA, disturbing the physiological variations of their diameter that occur during the hormonal cycle and pregnancy. This may explain the cases of smallness for age observed in animal and human. In animal, a high rate of low weight at birth (80\%) was observed after complete and bilateral embolization of uterine arteries with poly (vinyl-alcohol) particles [7]. It was clearly related to chronic inflammation, fibrosis and stenosis of the uterine arteries [8] which durably impair the uterine arteries to adapt their flow to the foetal growth. In human, the percentage of newborns that are small for gestational age varies according to authors, $22 \%$ in Pron et al. [9] study, $14 \%$ in Kim et al. [4] study and $7 \%$ in Goldberg et al. [10], probably due to less extensive embolization than in animal.

Resorbable embolization particles made from gelatin sponge have been used as an alternative to non degradable particles. The clinical results are similar to those of non degradable particles [11]. However gelatin particles are not devoid of disadvantages. Their degradation lasts from 3 weeks to 4 months and is accompanied by a chronic inflammatory response, and possible generation of arterial aneurisms on the site of arterial remodeling [12,13]. The UA recanalization estimated 4 months after embolization by magnetic resonance angiography is present in $88 \%$ arteries but the percentage of diameter recovery is unknown [14]. The fertility after embolization with gelatin has not been evaluated, either in animal or in human.

To prevent the deleterious effects inherent to all these non degradable and degradable particles, a short-life occlusive agent could be proposed. It could play its role as a flow blocker during a time duration sufficient to yield a tumor ischemia, leading to a tumor necrosis, and thereafter degrade quickly without leaving any inflammation or stenosis of the UA. Unfortunately, the minimal time of occlusion required for getting a fibroid necrosis is not well defined. Lichtinger observed by laparoscopy 
that a bilateral UA transient clamp during 26min (min-max 10$59 \mathrm{~min}$ ) resulted in a complete blanching of the uterus, which was reversible at clamp opening [15]. A temporary uterine arteries occlusion varying from 5 to 7 hours has been proposed as a surgical alternative to UFE [16-18]. From these data, we can hypothesize that the minimal duration for achieving a non reversible ischemia should be comprised between one hour and 7 hours.

The first results obtained in animal with embolization microspheres which degrade in vitro and in vivo in 24 hours [19] vs a non degradable microspheres as control are promising [20]. On the angiographic control at one week, there was a complete recanalization of $\mathrm{UA}$; the arterial flow and uterine parenchymography was similar to pre-embolization [20]. There was no structural alteration of the arterial wall, no residual microsphere and no inflammation. There was similar degree of uterus necrosis in myometrium and endometrium after embolization with resorbable microspheres and non degradable control. Conversely, with non degradable control, there were arterial blood flow reductions and defects of parenchymography and an inflammatory reaction.

These results suggest that the duration of arterial occlusion obtained with a particle which degrades within $24 \mathrm{H}$ would be sufficient to achieve both an ischemic necrosis of fibroids and a full recanalization of UA [20]. The efficacy of these degradable particles on fibroid necrosis and UA recanalization shall now be estimated with clinical trials.

\section{References}

1. Casele HL, Laifer SA (1997) Successful pregnancy after bilateral hypogastric artery ligation. A case report. J Reprod Med 42(5): 306308.

2. Nizard J, Barrinque L, Frydman R, Fernandez H (2003) Fertility and pregnancy outcomes following hypogastric artery ligation for severe post-partum haemorrhage. Hum Reprod 18(4): 844-848.

3. Cordonnier C, Ha-Vien DE, Depret S, Houfflin-Debarge V, Provost N, et al. (2002) Foetal growth restriction in the next pregnancy after uterine artery embolisation for post-partum haemorrhage. Eur J Obstet Gynecol Reprod Biol 103(2): 183-184.

4. Kim MD, Kim NK, Kim HJ, Lee MH (2005) Pregnancy following uterine artery embolization with polyvinyl alcohol particles for patients with uterine fibroid or adenomyosis. Cardiovasc Intervent Radiol 28(5): 611-615.

5. Ahmad I, Ray CE, Conyers C (2003) Transvaginal sonographic appearance of thrombosed uterine arteries after uterine artery embolization: the "White Snake" sign. J Clin Ultrasound 31(8): 401-406.
6. Das R, Gonsalves M, Vlahos I, Manyonda I, Belli AM (2013) MRI assessment of uterine artery patency and fibroid infarction rates 6 months after uterine artery embolization with nonspherical polyvinyl alcohol. Cardiovasc Intervent Radiol 36(5): 1280-1287.

7. Laurent A, Wassef M, Namur J, Martal J, Labarre D, et al. (2009) Recanalization and particle exclusion after embolization of uterine arteries in sheep: a long-term study. Fertil Steril 91(3): 884-892.

8. Laurent A, Pelage JP, Wassef M, Martal J (2006) Fertility after Bilateral Uterine Artery Embolization in Sheep model. Fertil Steril 89(5 Suppl): 1371-1383.

9. Pron G, Mocarski E, Bennett J, Vilos G, Common A, et al. (2005) Pregnancy after uterine artery embolization for leiomyomata: the ontario multicenter trial. Obstet Gynecol 105(1): 67-76.

10. Goldberg J, Pereira L, Berghella V (2002) Pregnancy after uterine artery embolization. Obstet Gynecol 100(5 Pt 1): 869-872.

11. Toda A, Sawada K, Osuga K, Maeda N, Higashihara H, et al. (2016) Efficacies of uterine artery embolization for symptomatic uterine fibroids using gelatin sponge: a single-center experience and literature review. Int J Womens Health 8: 397-404.

12. Berenstein A, Russell E (1981) Gelatin sponge in therapeutic neuroradiology: a subject review. Radiology 141(1): 105-112.

13. Louail B, Sapoval M, Bonneau M, Wasseff M, Senechal Q et al. (2006) A new porcine sponge material for temporary embolization: an experimental short-term pilot study in swine. Cardiovasc Intervent Radiol 29(5): 826-831.

14. Katsumori T, Kasahara T, Kin Y, Ichihashi S (2007) Magnetic resonance angiography of uterine artery: changes with embolization using gelatin sponge particles alone for fibroids. Cardiovasc Intervent Radiol 30(3): 398-404.

15. Lichtinger M, Burbank F, Hallson L, Herbert S, Uyeno J, et al. (2003) The time course of myometrial ischemia and reperfusion after laparoscopic uterine artery occlusion--theoretical implications. J Am Assoc Gynecol Laparosc 10(4): 554-563.

16. Istre O, Hald K, Qvigstad Em (2004) Multiple myomas treated with a temporary, noninvasive, Doppler-directed, transvaginal uterine artery clamp. J Am Assoc Gynecol Laparosc 11(2): 273-276.

17. Lichtinger M, Herbert S, Memmolo A (2005) Temporary, transvaginal occlusion of the uterine arteries: a feasibility and safety study. J Minim Invasive Gynecol 12(1): 40-42.

18. Vilos GA, Vilos EC, Abu-Rafea B, Hollett-Caines J, Romano W (2010) Transvaginal Doppler-guided uterine artery occlusion for the treatment of symptomatic fibroids: summary results from two pilot studies. J Obstet Gynaecol Can 32(2): 149-154.

19. Louguet S, Verret V, Bédouet L, Servais E, Pascale F, et al. (2014) Poly (ethylene glycol) methacrylate hydrolyzable microspheres for transient vascular embolization. Acta Biomater 10(3): 1194-1205.

20. Verret V, Pelage JP, Wassef M, Louguet S, Servais E, et al. (2014) A novel resorbable embolization microsphere for transient uterine artery occlusion: a comparative study with trisacryl-gelatin microspheres in the sheep model.J Vasc Interv Radiol 25(11): 1759-1766. 
This work is licensed under Creative Commons Attribution 4.0 Licens

DOI: 10.19080/JGWH.2017.05.555656
Your next submission with Juniper Publishers will reach you the below assets

- Quality Editorial service

- Swift Peer Review

- Reprints availability

- E-prints Service

- Manuscript Podcast for convenient understanding

- Global attainment for your research

- Manuscript accessibility in different formats

( Pdf, E-pub, Full Text, Audio)

- Unceasing customer service

Track the below URL for one-step submission https://juniperpublishers.com/online-submission.php 